\title{
HISTOLOGICAL CONSEQUENCES OF CONSUMPTION OF ENERGY DRINK ON RENAL TUBULES
}

\author{
Ammara Rasheed, Imtiaz Aslam*, Raafea Tafweez**, Muhammad Rizwan Bashir Kiani***, Muhammad Kamran Ameer***, \\ Arslan Akbar Saeed \\ Nishtar Medical University, Multan Pakistan, *Fatima Jinnah Medical University, Lahore Pakistan, **King Edward Medical University, Lahore Pakistan, \\ ${ }^{* * *}$ Army Medical College/National University of Medical Sciences (NUMS) Rawalpindi Pakistan, \\ ****Multan Medical and Dental College, Multan Pakistan
}

\begin{abstract}
Objective: To investigate the outcomes of energy drink on renal tubules of albino rats. Study Design: Laboratory-based experimental study.

Place and Duration of Study: King Edward Medical University, Lahore from Aug 2018 to Dec 2019.

Methodology: Group A and B were experimental groups received $1.5 \mathrm{ml} / \mathrm{kg}$ and $2.2 \mathrm{ml} / \mathrm{kg}$ body weight of energy drink, respectively. Group C received $1 \mathrm{ml} / \mathrm{kg}$ body weight of distilled water. Comparison among groups was made by applying One-Way ANOVA for quantitative variables. Tukey' test was used for post hoc analysis. For qualitative variables, chi-square test was applied to make comparison among groups

Results: The mean initial and final weight of animals was around $152.7 \pm 5.3 \mathrm{~g}$ and $171.9 \pm 5.1 \mathrm{~g}$, respectively. The mean paired kidney weight, relative tissue weight index, length and width of kidneys for all three groups were found insignificant. Microscopic examination showed tubular vacuolization in groups A and B showing $p$-value of 0.027 .

Conclusion: Consumption of energy drinks results in histopathological injury of epithelial cells of renal tubules.
\end{abstract}

Keywords: Caffeine, Energy drink, Renal tubules, Renal vacuolization, Taurine.

How to Cite This Article: Rasheed A, Aslam I, Tafweez R, Kiani MRB, Ameer MK, Saeed AA. Histological Consequences of Consumption of Energy Drink on Renal Tubules. Pak Armed Forces Med J 2021; 71(5): 1736-1740. doi: https://doi.org/10.51253/pafmj.v71i5.6326

This is an Open Access article distributed under the terms of the Creative Commons Attribution License (https://creativecommons.org/licenses/by-nc/4.0/), which permits unrestricted use, distribution, and reproduction in any medium, provided the original work is properly cited.

\section{INTRODUCTION}

Energy drinks are kind of beverages containing stimulant substances with caffeine as integral part. After popularity of soft drinks, beverages containing more stimulant ingredients gather more recognition in 19th century. ${ }^{1}$ These energy drinks are traded with assumption of increased physical and mental energy and alertness.

There is a worry about the hazards of consumption of these energy boosting drinks on users' physical well-being due to the elevated amounts of caffeine, taurine, sugar, and other ingredients (like guarana, ginseng and herbal contents), which act as stimulant of vital systems of body. ${ }^{2}$ Young people especially sports men, students, and military persons are more likely to be regular consumers of energy boosting drinks. ${ }^{3}$ Studies have established link between consumption of energy drinks and other precarious habits (like usage of alcohol and addictive drugs, violence and smoking) among teenagers and young population. ${ }^{4}$ Prime cause of trouble associated with energy beverages consump-

Correspondence: Dr Ammara Rasheed, Department of Anatomy, Nishtar Medical University, Multan Pakistan

Received: 19 Feb 2021; revision received: 22 Apr 2021; accepted: 27 Apr 2021 tion is excessive caffeine content which can cause sleep disturbances, anxiety, effects on digestive system, and other cardiac and neural symptoms like tachycardia, seizures and headache ${ }^{5}$.

Previous researches reported acute renal damage along with deranged serum urea and creatinine levels caused by high intake of energy drinks; it is likely due to increased caffeine and taurine and may be interaction of these two with other ingredients. ${ }^{6}$ Worldwide, prevalence of chronic kidney disease among young people is rising at alarming rate. In Pakistan, chronic renal disease has incidence of $10.5 \%$ among young population $<30$ years of age group, reported by Alam et $a l^{7}$. This incidence is increasing due to unhealthy dietary habits including usage of sugar rich caffeine containing beverages. ${ }^{8}$ Some other studies reported acute hepatic injury accredited to niacin and other herbal stimulants. ${ }^{9}$ These tissue injuries depend upon the amount of drink which varies from individual to individual. Apart from biochemical serum parameters histology of liver and kidneys are of great concern to determine the extent of injury due to energy drink. The objective of this study was to investigate the outcomes of energy drink on renal tubules of albino rats. 


\section{METHODOLOGY}

This experimental animal study was performed in Anatomy department, King Edward Medical University, Lahore, from August 2018 to December 2019 after taking approval from Institutional review board under 471/RC/KEMU \& No F4-3/CPS-ID/BMS/RAEC/14/.

Inclusion Criteria: Adult healthy albino male rats, 812 weeks old, weighing 130-160 grams were included.

Exclusion Criteria: Apprently sick animals were excluded

Group A and B were experimental groups received $1.5 \mathrm{ml} / 100 \mathrm{~g}$ and $2.2 \mathrm{ml} / 100 \mathrm{~g}^{10}$, body weight of energy drink, respectively. Group C received $1 \mathrm{ml} / \mathrm{kg}$ body weight of distilled water.The rats were sacrificed on $60^{\text {th }}$ day of experiment after 24 hours of last dose. Kidneys were removed after dissection. Gross examination of kidneys were done specimens were placed in labelled jars. Microscopic examination was done after histological processing and Periodic acid-Schiff stain, hematoxylin and eosin staining. All parameters were noted as follows, Tubular vacuolization was observed as cytoplasmic vacuolization characterized by the presence of clear vacuoles in renal tubular epithelial cells ${ }^{11}$, graded as, absent (0), mild (1) $<25 \%$ tubules involved in whole slide of tis-sue. Moderate (2) $26-50 \%$ tubules involved in whole slide of tissue. Severe (3) $>50 \%$ tubules involved in whole slide of tissue. Tubular brush border loss as luminal border loss documented by help of Periodic acid Schiff stain ${ }^{12}$. Tubular atrophy observed as the presence of tubules having thick irregular basement membranes, flattened cells and contracted lumen, or decrease in tubular diameter $>50 \%$ as compare to non-atrophic tubules present in vicinity ${ }^{13}$.

Tubular necrosis observed as shedding of tubular cells with disrupted basement membrane ${ }^{14}$.

Analysis of data was done by SPSS version 20. Mean \pm SD was used for quantitative variables. Qualitative parameters included vascular engorgement or any gross abnormality of kidneys and microscopic parameters like tubular vacuolization, tubular brush border loss, tubular atrophy, tubular necrosis. Quantitative included weight of animal in grams, paired kidney weight in grams, relative tissue weight index, length and width of kidneys in millimeters. For qualitative variables, frequencies and percentages were used. For quantitative variables, comparison among groups was made by applying One Way ANOVA. Tukey' test was used for post hoc analysis. For qualitative variables, chi-square test was applied to make comparison among groups. The $p$-value of $\leq 0.05$ was considered as statistically noteworthy.

\section{RESULTS}

Out of 90 animals, mean initial weight of animals was around 150 grams with $151.2 \pm 5.7 \mathrm{~g}$ in group A, $152.1 \pm 5.7 \mathrm{~g}$ in group B and $152.7 \pm 5.3 \mathrm{~g}$ group $\mathrm{C}$. The difference among three groups at initial stage of experiment was insignificant with $p$-value 0.577 .

The mean final weight of animals was around 170 grams with $171.7 \pm 6.9 \mathrm{~g}$ in group A, $171.9 \pm 6.3 \mathrm{~g}$ in group $B$ and $172.7 \pm 5.1 \mathrm{~g}$ in group $\mathrm{C}$. The difference among three interventional groups at final stage was insignificant with $p$-value 0.798 .

The mean paired kidney weight for group A was $1.81 \pm 0.16 \mathrm{~g}, 1.82 \pm 0.17 \mathrm{~g}$ for group B and $1.76 \pm 0.17 \mathrm{~g}$ for group C. Difference among all groups was found insignificant with $p$-value 0.354 .

The surface and color of kidneys was found smooth and normal respectively, for all animals in all three groups. Therefore, being constant these parameters were not tested for significance among the three groups.

The mean relative tissue weight index of group A was $1.051 \pm 0.071$ and for group B was $1.060 \pm 0.082$. The mean index for control group $C$ was $1.021 \pm 0.098$ and difference among interventional groups was not significant with $p$-value 0.177 .

The mean length of right kidney for group $A$ and group B was same as $10.52 \pm 0.65 \mathrm{~mm}$ and $10.43 \pm 0.63$ $\mathrm{mm}$ for group $\mathrm{C}$. The mean length of left kidney for group A and group B was same as $10.44 \pm 0.69 \mathrm{~mm}$ and $10.38 \pm 0.67 \mathrm{~mm}$ for group C. The difference among three groups for right and left kidneys was insignificant with $p$-values 0.833 and 0.908 respectively.

The mean width of right kidney for group $\mathrm{A}$ and $B$ was same as $5.63 \pm 0.62 \mathrm{~mm}$ and $5.49 \pm 0.46 \mathrm{~mm}$ for group $\mathrm{C}$. The mean width of left kidney for group A and $B$ was same as $5.57 \pm 0.55 \mathrm{~mm}$ and $5.49 \pm 0.47 \mathrm{~mm}$ for group C. The differences among three groups for right and left kidneys were insignificant with $p$-values 0.533 and 0.763 respectively. There was no vascular engorgement or any other abnormality found on gross examination of kidney specimens.

Tubular brush border loss, tubular atrophy and tubular necrosis were found absent in all animals of three groups (Figure-1, 2 and 3). Being constant, these para-meters were not tested for significance among three groups. 
The group A had 20 (66.6\%) cases with mild vacuolization and $3(10 \%)$ with moderate vacuolization.

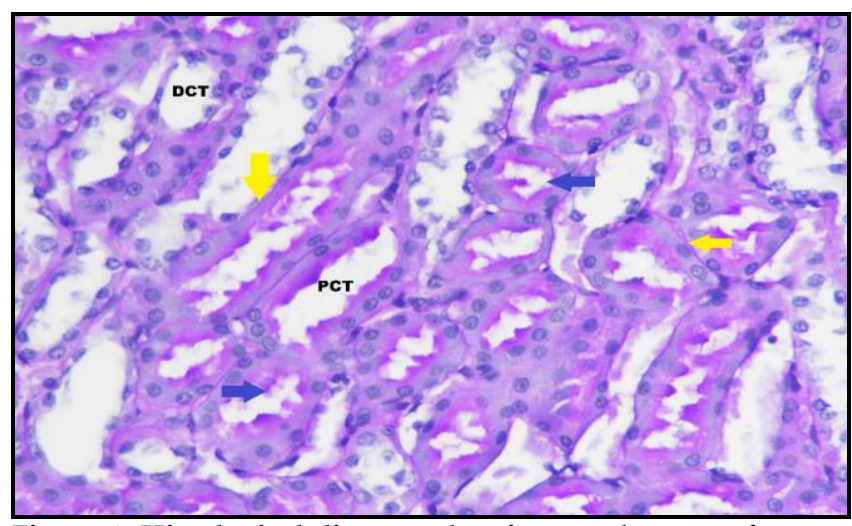

Figure-1: Histological diagram showing renal cortex of group $C$ with intact basement membranes (yellow arrows) and brush border of renal tubules (blue arrows) DCT represents distal convoluted tubules, PCT shows proximal convoluted tubules. PAS stain.400X.

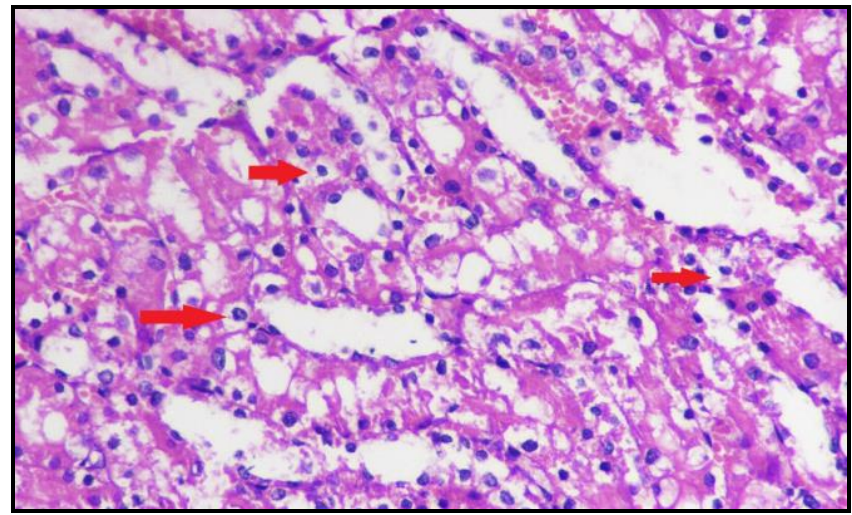

Figure-2: Histological diagram showing renal cortex of group B with multiple tubules. Red arrow showing perinuclear vacuolization in epithelial cells of renal tubules. H\&E stain. 400X.

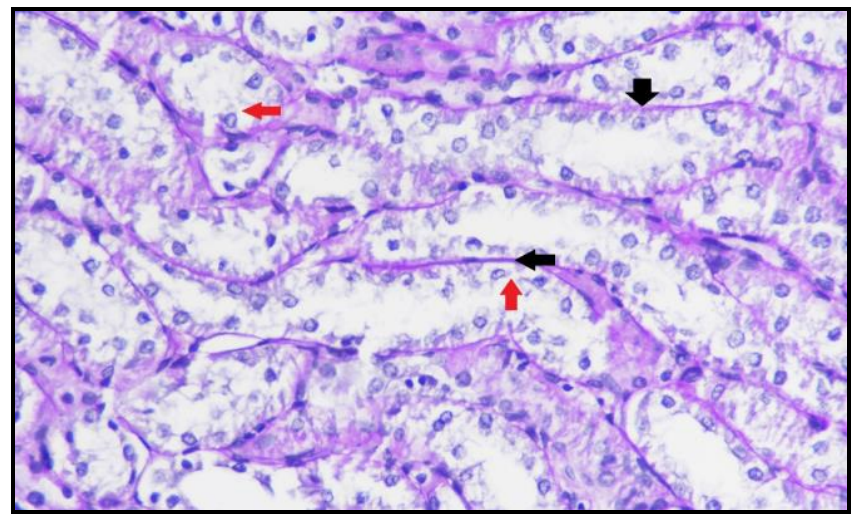

Figure-3: Histological diagram showing renal cortex of group $B$ with intact basement membranes and brush border of renal tubules (black arrow). RC denotes renal corpuscle, DCT represents distal convoluted tubules, PCT shows proximal convoluted tubules. Red arrow showing perinuclear vacuolization in renal epithelial cells. PAS stain.400X.
While, the group B had 13 (43.3\%) with mild vacuolization and $12(40 \%)$ with moderate vacuolization (Figure-2 \& 3). The difference of group A and B from group $\mathrm{C}$ was highly significant with $p$-value $<0.001$ shown in the Table.

Table: Status and comparison for tubular vacuolization for animals at final stage of experiment in three study groups.

\begin{tabular}{l|c|c|c|c}
\hline \multirow{2}{*}{ Groups } & Absent & Mild & Moderate & \multirow{2}{*}{$\boldsymbol{p}$-value } \\
\cline { 2 - 4 } & \multicolumn{3}{|c|}{ n (\%) } & \\
\hline A & $7(23.3)$ & $20(66.7)$ & $3(10)$ & \multirow{2}{*}{$<0.001$} \\
\hline B & $5(16.7)$ & $13(43.3)$ & $12(40)$ & \\
\hline C & $30(100)$ & - & - & \\
\hline
\end{tabular}

\section{DISCUSSION}

Consumption of energy drinks has picked up steam during previous few years. One of the sound reasons is, attractive marketing strategies of companies making these types of drinks. Target consumers of energy drinks are teenagers and young adults. These young people are consuming these drinks at an alarmingly high amount. ${ }^{15}$

A comprehensive research project was carried out to see the outcomes of energy drink on renal tissue of albino rats.

In our study, the difference in the initial mean weights among three groups and its difference with the mean final weights at the end of experiment were statistically insignificant. This finding collaborates with study by Al-Shaikan, due to thermogenic activity of caffeine, no considerable weight change with energy drink is observed. ${ }^{16}$ However, contrary to above observation, Eltahir et al showed significant weight gain in rats treated with energy drink for period of four weeks. ${ }^{17}$

Insignificant difference was found among groups for weight of kidney as well as for relative tissue weight index. Study by Alansari suggested similar findings for relative tissue weight and kidney weight. ${ }^{18,19}$

The difference among three groups for length and width of right and left kidneys was insignificant in present study. These findings are similar to study conducted by Mansy et al, showed no significant effect of use of energy drink, for 12 weeks duration, on length and width of kidneys of Sprague Dawley rats ${ }^{10}$. Another study of effect of energy drink on albino rabbits for duration of 30 days, carried out by Salih et al, showed similar findings regarding length and width of kidneys. ${ }^{20}$

There was no vascular engorgement of kidneys on naked eye observation, in the animal of any groups 
Energy Drink and Renal Tubules

and there was no other gross abnormality of kidneys found in any animal of all groups. Present results are in favor of findings reported by Mansy et al, and Salih et al, which were carried out to see effect of caffeinated energy drink on kidneys of Sprague Dawley albino rats and rabbits, respectively. ${ }^{10,20}$ While in contrast to findings presented by Costa-Valle et al, showed vascular congestion and engorgement in kidneys of rats treated with energy drink in combination of alcohol for period of one month. ${ }^{21}$

Mild to moderate increase in tubular vacuolization was found in our research project. These findings were consistent with results shown by Mansy et al,10 and Salih et al, ${ }^{20}$ in their studies. The possible reason is stated that caffeine raises urea, uric acid and creatinine via acting as inhibitor of $\mathrm{A} 2 \mathrm{~A}$ adenosine receptors producing oxidative stress, causing stimulation of xanthine oxidase which in turn, activated the oxidation of xanthine to uric acid, and formation of superoxide anion and $\mathrm{H} 2 \mathrm{O} 2$. The reaction between $\mathrm{H} 2 \mathrm{O} 2$ with $\mathrm{O} 2$ produces free radicals, resulting in the development of inflammatory changes causing cellular injury and vacuolization and negative effects in renal function and structure and other possible reason of cellular vacuolization may be potential reaction of taurine with caffeine. ${ }^{22}$ While present study results are contradictory to study presented by Elizabeth et al, who showed normal histological features of kidney. ${ }^{23}$ Another study conducted by Eltahir et al, ${ }^{17}$ which showed deranged serum urea and creatinine with normal histology of renal tubules of rats after administration of caffeinated energy drink for three weeks. Thus it might take longer time to bring changes in histology of kidneys.

Histological parameters including tubular atrophy, tubular brush border loss and tubular necrosis were absent in kidney tissues in present study which is in consistent with study by Eltahir et al. ${ }^{17}$ While in contrary to studies conducted by Mansy et al, and Salih et $a l$, and Sara et al, who showed degeneration of renal tubular epithelium, tubular atrophy and interstitial hemorrhage in renal tissue. ${ }^{10,20,24}$ Thus it might be due to variable dose of energy drink and variable duration of experiment. Among all ingredients of energy drinks, mechanism of action on the body is almost interpreted. The effects of herbal ingredients including guarana and ginseng are still poorly unclear. The same paucity of studies exists for taurine and other ingredients present in energy drinks, as well as, for the additive effects of these substances with each other and other substances such as alcohol or drugs.

\section{CONCLUSION}

Energy drinks with differing doses induces histopathological changes in renal tubular cells. Further studies are recommended to be carried out on energy drink for variable duration with special histological staining procedures.

\section{Conflict of Interest: None.}

\section{Authors' Contribution}

AR: Conception, designing experimentation, analysis of results, manuscripts writing, IA: Experimentation, analysis of results, critical review, RT: Interpretation discussion, results, cirtical review, MRBK: Material analysis, proof reading, MKA: Material analysis, manuscript review, AAS: Experimentation, facilitated for reagents.

\section{REFERENCES}

1. Mahoney CR, Giles GE, Marriott BP, Judelson DA, Glickman EL, Geiselman PJ, et al. Intake of caffeine from all sources and reasons for use by college students. Clin Nutr 2019; 38(2): 668675.

2. Rahamathulla MP. Prevalence, side effects and awareness about energy drinks among the female university students in Saudi Arabia. Pak J Med Sci 2017; 33(2): 347-352.

3. Sommers KR, Savtikova A. Cardiovascular and autonomic responses to energy drinks-clinical implications. J Clin Med 2020; 9(2): 431-436.

4. Benson S, Verste JC, Scholey A. Consumption patterns of alcohol and alcohol mixed with energy drinks in australian students and non-students. Nutrients 2020; 12(1): 149-155.

5. Nowak D, Goslinski M, Nowatkowska K. The effect of acute consumption of energy drinks on blood pressure, heart rate and blood glucose in the group of young adults. Int J Environ Res Public Health 2018; 15(3): 544-550.

6. Romagnani P, Remuzzi G, Glassock R, Levin A, Jager KJ. Chronic kidney disease. Nat Rev Dis Primers 2017; 23(3): 17088.

7. Alam A, Amanullah F, Ansari NB, Farrukh IL, Khan FS. Prevalence and risk factors of kidney disease in urban Karachi: baseline findings from a community cohort study. BMC Res Notes 2014; 7(1): 179-185.

8. Hill NR, Fatoba ST, Oke JL, Hirst JA, O'Callaghan CA. Global prevalence of chronic kidney disease - a systematic review and meta-analysis. PLoS One 2016; 11(7): e0158765.

9. Yacoub RA, Luczkiewicz D, Kerr C. Acute kidney injury and hepatitis associated with energy drink consumption: A case report. J Med Case Rep 2020; 14(1): 23-28.

10. Mansy W, Alogaiel DM, Hanafi M, Zakaria E. Effects of chronic consumption of energy drinks on liver and kidney of experimental rats. Trop J Pharm Res 2017; 16(12): 2849-2856.

11. Ding L, Li L,Liu S, Bao X, Dickman KG, Sell SS. Proximal tubular vacuolization and hypersensitivity to drug-induced nephrotoxicity in male mice with decreased expression of the NADPH-Cytochrome P450 Reductase. Toxicol Sci 2020; 173(2): 362-372.

12. Haraguchi R, Kohara Y, Matsubayashi K, Kitazawa R, Kitazawa S. New insights into the pathogenesis of diabetic nephropathy: proximal renal tubules are primary target of oxidative stress in diabetic kidney. Acta Histochem Cytochem 2020; 53(2): 21-31.

13. Zhu X, Li H, Liu Y, You J, Qu Z, Yuan S, et al. Tubular atrophy/ interstitial fibrosis scores of Oxford classification combinded with proteinuria level at biopsy provides earlier risk prediction in lgA nephropathy. Sci Rep 2017; 7(1): 1100. 


\section{Energy Drink and Renal Tubules}

14. Xu-Dubois YC, Ahmadpoor P, Brocheriou I. Microvasculature partial endothelial mesenchy-mal transition in early posttransplant biopsy with acute tubular necrosis identifies poor recovery renal allografts. Am J Transp-lant 2020; 20(9): 2400-2412.

15. Al-Basher GI, Aljabal H, Almeer RS, Allam AA, Mahmoud AM. Perinatal exposure to energy drink induces oxidative damage in the liver, kidney and brain, and behavioral alterations inmice offspring. Biomed Pharmacother 2018; 102(2): 798-811.

16. Al Saikhan FI. Hepatic \& renal toxicity of energy drinks,a serious health risk, wistar albino rats study. J Pharm Res Int 2020; 32(7): 48-53.

17. Eltahir HM, Alamri G, Alamri A, Aloufi A, Nazmy M, Elbadawy $\mathrm{H}$, et al. The metabolic disorders associated with chronic consumption of soft and energy drinks in rats. Acta Biochim Pol 2020; 67(1): 79-84.

18. Alansari AKA. Impact of Code Red energy drink on the functions and structure of the kidney of Wistar Albino rats: possible therapeutic effects of blueberry ethanolic extract. J Saudi Soc Food Nutr 2020; 13(1): 114-126.
19. Almehmadi AEBMG. Effect of "Red Bull" energy drink on some neurotransmitters content and histological structure of cerebral cortex in male albino rats. Life Sci J 2017; 14(1): 63-73.

20. Salih NA, Abdul-Sadaand IH, Abdulrahman NR. Histopathological effect of energy drinks (Red Bull) on Brain, Liver, Kidney, and Heart in Rabbits. Med J Babylon 2018; 15(1): 16-20.

21. Costa-Valle MT, Tonieto BD, Altknecht L, Cunha CD, Fão N. Energy drink and alcohol combination leads to kidney and liver alterations in rats. Toxicol Appl Pharmacol 2018; 355(2): 138-146.

22. Barcelos RP, Lima FD, Carvalho NR, Bresciani G, Royes LF. Caffeine effects on systemic metabolism, oxidative-inflammatory pathways, and exercise performance. Nutr Res 2020; 80(4): 1-17.

23. Elizabeth MA, Ebun O, Osahon, Roli OI, Augustine O. Caffeinated energy drink induces oxidative stress, lipid peroxidation and mild distortion of cells in the renal cortex of adult wistar rats. Eur J Pharm Med Res 2020; 7(6): 817-824

24. Bano SS, Ali S, Rana R, Ali H. Histological effects of caffeinated energy drink consumption and its withdra-wal on kidneys of experimental rats. J Islam Int Med Coll 2020; 15(2): 128-132. 